\title{
Relação entre biofilme, atividade de cárie e gengivite em crianças $\mathrm{HIV}^{+}$
}

\section{Relation between biofilm, caries activity and gingivitis in HIV+ children}

\author{
Apoena de Aguiar Ribeiro* \\ Maristela Portela** \\ Ivete Pomarico de Souza***
}

\begin{abstract}
RESUMO: A utilização de terapia medicamentosa em crianças infectadas pelo HIV $\left(\mathrm{HIV}^{+}\right)$vem promovendo a diminuição na prevalência de manifestações bucais em tecidos moles ao longo dos anos. Entretanto, observa-se uma constância na experiência de cárie e gengivite desta população, sobretudo devido à influência crônica de alguns fatores envolvidos no processo da infecção pelo HIV, como uso prolongado de medicamentos líquidos açucarados, dieta rica em carboidratos e repetidos episódios de internação. Assim, o objetivo do presente estudo foi avaliar se a qualidade e quantidade de biofilme representam um fator importante na atividade da doença cárie e gengivite neste grupo em especial. Após exame do biofilme (indice de biofilme; Ribeiro ${ }^{23}$, 2000), da atividade de cárie e gengivite de 56 crianças, de 0 a 14 anos, pacientes com diagnóstico definitivo de infecção pelo HIV, observou-se que somente $7(12,5 \%)$ não apresentavam biofilme visível clinicamente e 33 (58,9\%) apresentavam gengivite, com, em média, 4,44 superficies com sangramento. Quanto à doença cárie, $73,2 \%$ das crianças apresentavam lesões cariosas ativas. Verificou-se ainda a correlação entre o indice de biofilme, o estado gengival e a atividade das lesões cariosas (teste de correlação de Spearman, $r_{s}=+0,57$ e $r_{s}=+0,49$, respectivamente). Conclui-se, que nas crianças HIV + avaliadas, a qualidade e quantidade de biofilme sobre a superficie dental representam um importante fator na etiologia da atividade das doenças cárie e gengivite, podendo e devendo este ser trabalhado para que seja possivel restabelecer a saúde bucal destas crianças. UNITERMOS: Síndrome de imunodeficiência adquirida; Criança; Placa dentária; Cárie dentária; Gengivite.
\end{abstract}

\begin{abstract}
The utilization of medicines to treat HIV-infected children has been promoting a decrease in the prevalence of soft-tissue oral lesions, as years pass by. In contrast, it has been observed that the experience of caries and gingivitis is constant in this population, mostly because of the chronic influence of some factors involved in the HIV-infection process, such as the chronic utilization of sweetened liquid medicines and carbohydrate-enriched diet, as well as frequent episodes of hospitalization. So, the purpose of this study was to evaluate if the quality and quantity of biofilm are important factors in the activity of dental caries and gingivitis, also in this special group. After examination of the biofilm (biofilm index - Ribeiro ${ }^{23}, 2000$ ), the activity of caries and gingivitis was assessed in 56 children, aging from 0 to 14 years, who were patients with definitive diagnosis of HIV infection. It was observed that only 7 subjects $(12.5 \%)$ did not present with clinically visible biofilm, and $33(58.9 \%)$ presented with gingivitis, with the average of 4.44 bleeding sites. As to dental caries, $73.2 \%$ of the patients presented with active carious lesions. A strong correlation was verified between Biofilm Index, gingival status and active carious lesions (Spearman's correlation test, $r_{\mathrm{s}}=+0.57$ and $r_{s}=+0.49$, respectively). It was concluded that, also in HIV-infected children, the quality and quantity of biofilm over the dental surfaces are important etiologic factors related to the activity of caries and gingivitis. Biofilm should, thus, be controlled in order to reestablish the oral health of HIV-infected children.
\end{abstract}

UNITERMS: Acquired immunodeficiency syndrome; Child; Dental plaque; Dental caries; Gingivitis.

\section{INTRODUÇÃO}

A infecção pelo vírus HIV acarreta uma diminuição progressiva em número e atividade dos linfócitos $\mathrm{T} \mathrm{CD}_{4+}^{+}$, comprometendo a imunidade celular e deixando o hospedeiro susceptivel ao desenvolvimento de várias infecções oportunistas e neoplasmas ${ }^{22}$. Dentre as manifestações comuns em crianças infectadas pelo HIV, destacam-se a linfadenopatia, hepatomegalia, infecções oportunistas bacterianas ou virais, como pneumonia intersticial linfóide (LIP), meningite, abscesso e celulite $^{10}$. A cavidade bucal é particularmente susceptivel à infecção por possuir numerosos micro-

\footnotetext{
* Mestre em Odontopediatria da Universidade Federal do Rio de Janeiro; Professora da Disciplina de Odontopediatria da Universidade Estácio de Sá e da Universidade do Grande Rio.

** Mestranda em Odontopediatria; ${ }^{* * *}$ Professora Titular da Disciplina de Odontopediatria - Faculdade de Odontologia da Universidade Federal do Rio de Janeiro.
} 
Ribeiro A de A, Portela M, Souza IP de. Relação entre biofilme, atividade de cárie e gengivite em crianças HIV ${ }^{+}$. Pesqui Odontol Bras 2002;16(2):144-150.

organismos que proliferam em condições de imunossupressão, causando lesões fúngicas, virais e bacterianas, como a candidíase, eritema linear gengival, herpes, hipertrofia de parótidas, entre outras ${ }^{21}$.

A experiência de cárie e gengivite em crianças infectadas pelo HIV é elevada ${ }^{7,15}$, valor justificado pelo alto consumo de medicamentos contendo açúcar, dieta rica em carboidratos para reposição calórico-protéica ${ }^{18,19}$, menor imunidade contra bactérias cariogênicas ${ }^{18}$, diminuição do fluxo salivar ${ }^{24}$, hábitos inadequados de higiene bucal ${ }^{20}$ e falta de informação quanto às práticas de promoção de saúde bucal ${ }^{13}$. Assim, estas crianças representam um grupo em especial, em que muitos fatores moduladores da doença cárie e gengivite fazem parte do cotidiano de suas vidas. Alguns destes fatores podem ser trabalhados e modificados com a educação em saúde. Entretanto, o mesmo não pode ser feito com aqueles advindos da condição sistêmica, como a dieta e a imunidade.

O biofilme localizado em sítios específicos dos dentes é capaz de produzir uma variedade de irritantes locais após maturar-se, os quais, com o tempo, invariavelmente dissolvem o dente e alteram o periodonto ${ }^{27,28}$. Sabendo-se que o acúmulo de biofilme maduro é responsável por essa variação de saúde-doença, é razoável ver o grau de perturbação mecânica bucal como o fator intra-oral mais importante, o qual dita a possibilidade de desenvolvimento das comunidades bacterianas com potencial cariogênico e periodontopatogênico (biofilme não perturbado, maduro), capaz de causar os primeiros indícios de dissolução no esmalte e alterações aos tecidos periodontais em pacientes clinicamente saudáveis ${ }^{28,29}$.

Portanto, o objetivo do presente trabalho foi avaliar se a presença e qualidade do biofilme estão correlacionados com a atividade de cárie e presença de gengivite em crianças soropositivas para o $\mathrm{HIV}$, atendidas em dois hospitais públicos da cidade do Rio de Janeiro.

\section{MATERIAL E MÉTODO}

A população estudada foi compreendida por 56 crianças, com idade entre 0 e 14 anos, de ambos os sexos, atendidas no Ambulatório de AIDS pediátrica de dois hospitais públicos da cidade do Rio de Janeiro. Todas as crianças, inclusive aquelas com idade inferior a 18 meses, apresentavam diagnóstico definitivo de infecção pelo HIV, de acordo com os critérios definidos pelo Centers for Disease Control $^{3}$ (dado extraído do prontuário médico). Este es- tudo recebeu aprovação do Comitê de Ética do Núcleo de Estudos de Saúde Coletiva (NESC), da Universidade Federal do Rio de Janeiro.

Após o preenchimento do consentimento escrito livre e esclarecido, os responsáveis foram entrevistados (para obtenção de dados relacionados à identificação do paciente, história médica e odontológica) por um examinador (A.A.R.) ou por uma anotadora, previamente calibrada, que recebeu treinamento para que, durante a realização das perguntas não houvesse indução na obtenção das repostas.

Todos os exames foram realizados por um único examinador (A.A.R.). A magnitude do erro diagnóstico foi estimada através de duplo-exame de cárie ${ }^{2}$, com confiabilidade de 94,6\%; e do teste Kappa, obtendo-se um escore igual a 0,74. O exame das condições bucais foi realizado em uma sala do hospital, sob luz artificial. Nenhum exame radiográfico foi realizado. Foi avaliada a qualidade do biofilme visivel nas superficies dos dentes e registrada em um prontuário odontológico, de acordo com o índice de biofilme proposto por Ribeiro ${ }^{23}$ (2000) (Figura 1). O biofilme era classificado como fino quando somente pudesse ser identificado após secagem da superficie dental. Já o biofilme espesso era aquele identificado facilmente, firmemente aderido à superficie dental.

As crianças que receberam o escore 0 foram consideradas como apresentando controle de biofilme excelente, enquanto os escores 1 e 2 do índice foram considerados satisfatórios, por apresentar somente biofilme fino e facilmente removido (imaturo). Já os escores 3, 4 e 5 representaram o controle mecânico deficiente, por apresentarem biofilme espesso e firmemente aderido (maduro).

O exame da condição gengival foi realizado utilizando-se uma sonda periodontal estéril, com o objetivo de verificar a presença de inflamação gengival e a eficiência no controle de biofilme caseiro. Foram atribuídos escores, desenvolvidos para o presente estudo (Quadro 1). Além disso, o número de faces que apresentavam sangramento espontâneo e/ou provocado também foi anotado após o exame do estado da gengiva circundante a todos os dentes presentes na boca.

Para o exame da atividade das lesões de cárie, todas as superficies dos dentes presentes na boca foram examinadas, após limpeza profissional com a escova do próprio paciente e dentifrício fluoretado. Durante o exame, utilizou-se um espelho plano, sonda exploradora $n^{\circ} 5$ de ponta romba para 
Ribeiro A de A, Portela M, Souza IP de. Relação entre biofilme, atividade de cárie e gengivite em crianças HIV ${ }^{+}$. Pesqui Odontol Bras 2002;16(2):144-150.
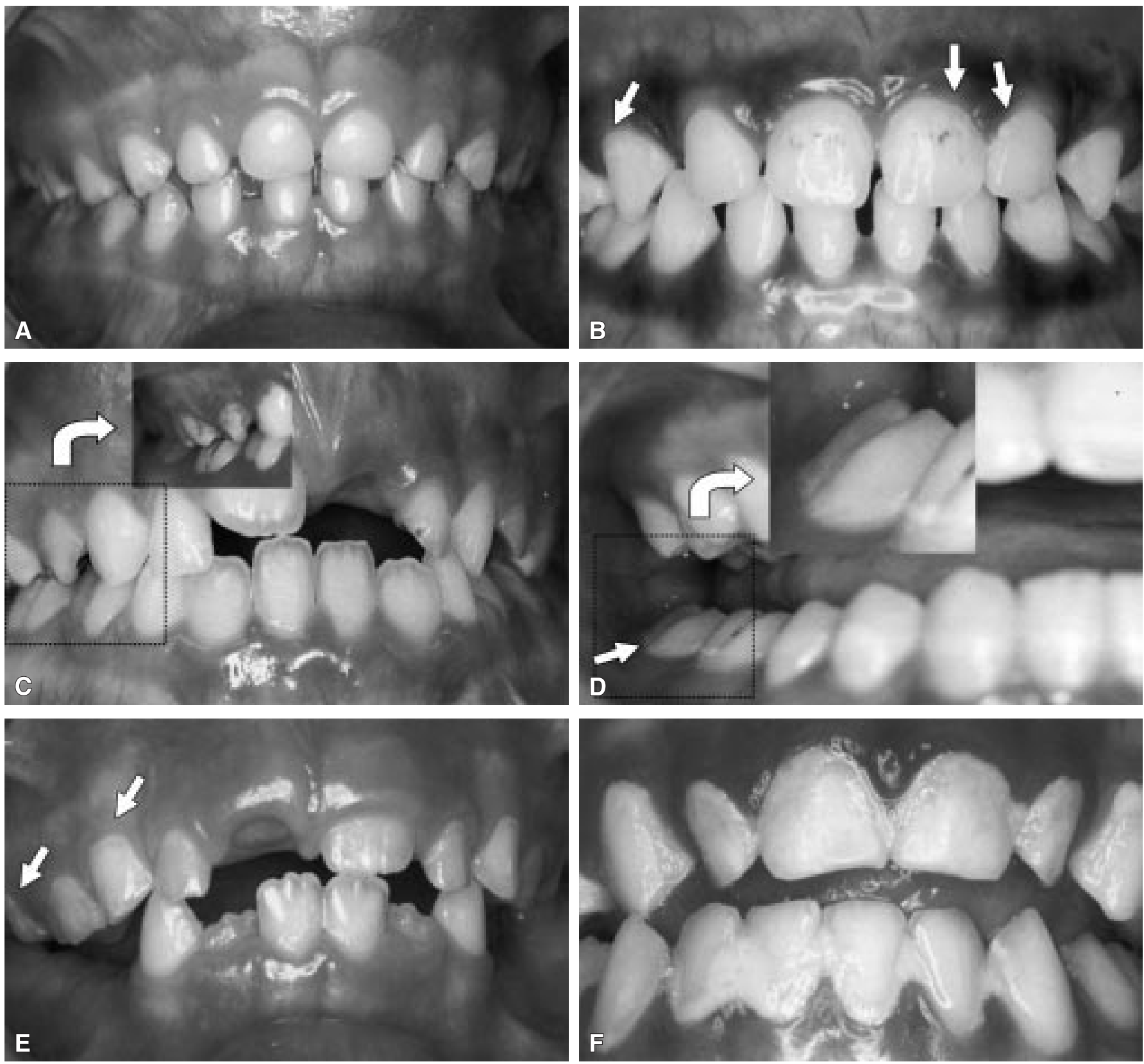

FIGURA 1 - Índice de biofilme de Ribeiro ${ }^{23}, 2000$. A: ausência de biofilme visivel. B: biofilme fino em dentes anteriores ou posteriores. C: biofilme fino em dentes anteriores e posteriores. D: biofilme espesso em dentes posteriores ou anteriores. E: biofilme espesso em dentes posteriores e fino em anteriores ou espesso em anteriores e fino em posteriores. F: biofilme espesso em dentes posteriores e anteriores.

remoção de biofilme dos sulcos e fissuras dentais, gaze para secagem das superficies dentais, e uma lanterna como fonte de luz. Para o exame das superficies proximais, onde suspeitou-se de presença de doença (através da alteração na cor do esmalte e/ou presença de gengivite interpapilar $\left.{ }^{9}\right)$, foi colocado um elástico separador, o qual passava pelo ponto de contato entre o dente em questão e seu vizinho, para que a superficie pudesse ser melhor inspecionada na consulta seguinte. As superficies dentais foram examinadas e diagnosticadas, de acordo com as descrições de Carvalho et al. ${ }^{6}$ (1992) e Bjorndal et al. ${ }^{4}$ (1997), para lesões em esmalte e dentina, respectivamente. Os aspectos destas superfícies foram então registrados através de um índice estabelecido para o presente traba- 
Ribeiro A de A, Portela M, Souza IP de. Relação entre biofilme, atividade de cárie e gengivite em crianças HIV ${ }^{+}$. Pesqui Odontol Bras 2002;16(2):144-150.

QUADRO 1 - Escores utilizados para avaliação da condição gengival das crianças examinadas, soropositivas para o HIV.

\begin{tabular}{|c|l||}
\hline \hline Escores & \multicolumn{1}{|c||}{ Condição gengival } \\
\hline 0 & $\begin{array}{l}\text { Gengiva clinicamente saudável, não apresenta } \\
\text { sangramento espontâneo ou provocado, após ser } \\
\text { sondada }\end{array}$ \\
\hline 1 & $\begin{array}{l}\text { Gengiva com sangramento após a realização da } \\
\text { sondagem (sangramento provocado) }\end{array}$ \\
\hline 2 & Gengiva com sangramento espontâneo \\
\hline
\end{tabular}

TABELA 1 - Resultados descritivos das superfícies quanto à presença e atividade de lesões cariosas das crianças soropositivas para o HIV examinadas.

\begin{tabular}{l|c|c|c|c}
\hline \hline \multirow{2}{*}{$\begin{array}{l}\text { Características } \\
\text { das superfícies }\end{array}$} & \multicolumn{4}{|c}{ Estatísticas descritivas } \\
\cline { 2 - 5 } & Média & $\begin{array}{c}\text { Desvio } \\
\text { padrão }\end{array}$ & $\begin{array}{c}\text { Mínimo } \\
\text { (freqüência) }\end{array}$ & $\begin{array}{c}\text { Máximo } \\
\text { (freqüência) }\end{array}$ \\
\hline Ativas & 8,03 & 10,91 & 0 & 52 \\
\hline Inativas & 3,76 & 4,33 & 0 & 14 \\
\hline $\begin{array}{l}\text { Envolvimento } \\
\text { pulpar }\end{array}$ & 1,00 & 2,13 & 0 & 11 \\
\hline \hline
\end{tabular}

1ho, que atribui números ímpares para lesões em atividade, e pares, para lesões inativas, em ordem crescente de acometimento das estruturas dentais $^{23}$ (Quadro 2).

Após estes exames, todas as crianças foram inseridas em um programa de promoção de saúde bucal, baseado em remoção mecânica de biofilme para controle da doença cárie e retornos periódicos para acompanhamento e motivação ${ }^{23}$.

Para avaliação dos resultados, os dados foram armazenados num banco de dados do Programa Epi Info 6.04. Foram utilizados os testes qui-quadrado e correlação de Spearman.

\section{RESULTADOS}

Com relação a presença e maturação do biofilme sobre as superficies dentais, observou-se que somente 7 crianças $(12,5 \%)$ não o possuíam de forma visivel clinicamente (excelente controle de biofilme). Vinte e uma crianças $(37,5 \%)$ apresentaram indice de biofilme considerado satisfatório, ou seja, este mostrou-se apenas de aspecto fino (imaturo) e facilmente removido (escores 1 e 2 do índice de biofilme), $9(16,1 \%)$ apresentavam biofilme espesso em dentes anteriores ou posteriores (escores 3 e 4 do indice de biofilme), enquanto dezenove
QUADRO 2 - Escores utilizados para avaliação das superficies dentais das crianças examinadas, soropositivas para o HIV.

\begin{tabular}{||l|l||}
\hline 0 & Sadia \\
\hline 1 & $\begin{array}{l}\text { Cárie ativa em esmalte, sem cavitação (esmalte opaco } \\
\text { com mancha branca na superfície) }\end{array}$ \\
\hline 2 & $\begin{array}{l}\text { Cárie inativa em esmalte, sem cavitação (superfície } \\
\text { brilhante com graus diferentes de descoloração casta- } \\
\text { nha) }\end{array}$ \\
\hline 3 & $\begin{array}{l}\text { Cavitação ativa em esmalte (esmalte com superfície } \\
\text { branco-opaca, e com perda de continuidade da superfí- } \\
\text { cie) }\end{array}$ \\
\hline 4 & $\begin{array}{l}\text { Cavitação inativa em esmalte (superfície brilhante com } \\
\text { graus diferentes de descoloração castanha, com perda } \\
\text { de continuidade da superfície) }\end{array}$ \\
\hline 5 & $\begin{array}{l}\text { Cavitação ativa em esmalte/dentina (descoloração } \\
\text { amarela ou castanha, suave, e dentina úmida) }\end{array}$ \\
\hline 6 & $\begin{array}{l}\text { Cavitação inativa do esmalte/dentina (descoloração } \\
\text { castanho escuro, dura, e dentina seca) }\end{array}$ \\
\hline 7 & $\begin{array}{l}\text { Dente com possível envolvimento pulpar ou resto radi- } \\
\text { cular }\end{array}$ \\
\hline 8 & Restaurado \\
\hline 9 & Extraído \\
\hline
\end{tabular}

(33,9\%) apresentavam escore 5 do indice (biofilme espesso e firmemente aderido em dentes posteriores e anteriores).

Quanto ao estado gengival, 33 crianças (58,9\%) apresentaram sangramento espontâneo ou provocado - $2(3,6 \%)$ e 31 (55,3\%), respectivamente. Destas crianças com problemas gengivais, 4,44 superficies (desvio padrão de 6,97), em média, apresentavam sangramento.

Ao correlacionar o índice de biofilme e o estado gengival, pôde-se observar que a prevalência de inflamação esteve associada aos índices que apresentavam placa espessa e madura sobre as superfícies dentais, e esta associação foi estatisticamente significante (teste qui-quadrado, $\mathrm{p}<0,001$ ) (Gráfico 1). Através da observação da linha de tendência do Gráfico 2 é possivel verificar moderada correlação entre a qualidade do biofilme, expressa através do índice utilizado, e a média das superficies gengivais com sangramento provocado (teste de correlação de Spearman, $\left.r_{s}=+0,57\right)$.

Com relação à experiência de cárie, pôde-se observar que a prevalência de crianças (total de 54, pois 2 foram excluídas desta análise por não possuírem dentes) apresentando esta doença foi ele- 
Ribeiro A de A, Portela M, Souza IP de. Relação entre biofilme, atividade de cárie e gengivite em crianças HIV ${ }^{+}$. Pesqui Odontol Bras 2002;16(2):144-150.

vada $(\mathrm{n}=43 ; 79,6 \%$ da amostra). Onze crianças $(20,4 \%)$ não apresentavam cárie na dentição decídua e duas $(3,7 \%)$ não apresentavam esta doença na dentição permanente.

Outra característica observada foi a elevada prevalência de crianças apresentando superficies dentais com lesões cariosas ativas $(\mathrm{n}=39 ; 72,2 \%)$. Por meio da análise da Tabela 1, é possivel verificar os resultados estatísticos descritivos destas superficies ou dos dentes com possivel envolvimento pulpar.

Através da linha de tendência apresentada no Gráfico 3, é possivel verificar que a medida que se observava a presença de biofilme mais espesso e

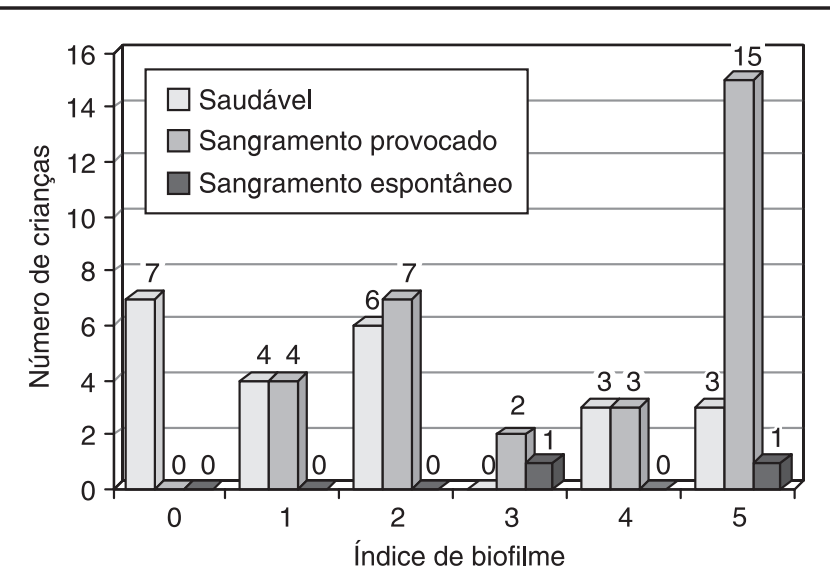

GRÁFICO 1 - Relação entre estado gengival e o índice de Ribeiro, Thylstrup, das crianças soropositivas para o HIV examinadas. Teste qui-quadrado: $\mathrm{p}<0,001$ (significativo).

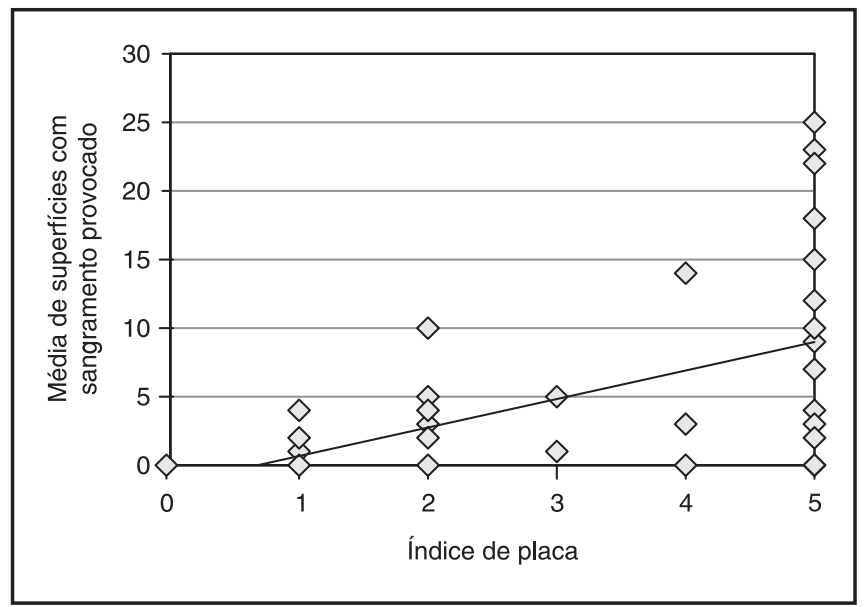

GRÁFICO 2 - Correlação entre média de superficies com sangramento gengival e o indice de Ribeiro, Thylstrup, das crianças soropositivas para o HIV examinadas. Teste de correlação de Spearman: $r_{s}=+0,57$. maduro sobre as superficies dentais, maior era o número de superficies apresentando lesões de cárie em atividade. Esta correlação pôde ser verificada através do teste de correlação de Spearman $\left(\mathrm{r}_{\mathrm{s}}=+0,49\right)$.

\section{DISCUSSÃO}

Alguns estudos do tipo caso-controle demonstraram que a saúde bucal das crianças infectadas pelo HIV é pior do que a apresentada por crianças saudáveis $^{30}$. A prevalência de crianças com gengivite $(58,9 \%)$ foi superior à relatada por Hamp et al. ${ }^{12}$ (1978), os quais encontraram a manifestação em $41,1 \%$ dos pacientes infantis clinicamente saudáveis. Ao reportar crianças cronicamente doentes, como é o caso deste estudo, provavelmente o grau de imunossupressão pode ter influenciado na resposta do tecido gengival, assim como verificaram Howell et al. ${ }^{14}$ (1996). Com relação a levantamentos com crianças brasileiras HIV+, Vieira et al. ${ }^{30}$ (1998) encontraram uma prevalência ainda maior de pacientes apresentando inflamação nos tecidos gengivais que o observado no presente estudo.

Foi demonstrada nos resultados apresentados uma correlação entre a presença de biofilme maduro e gengivite, corroborando com os trabalhos de diversos autores que afirmaram ser o biofilme maduro sobre a superficie dental próxima à margem gengival o fator etiológico da gengivite ${ }^{11,17}$. $\mathrm{O}$ trabalho de Cancro, Fishman ${ }^{5}$ (1995) relatou que nem todos os pacientes com gengivite desenvolverão periodontite, porém toda periodontite começou

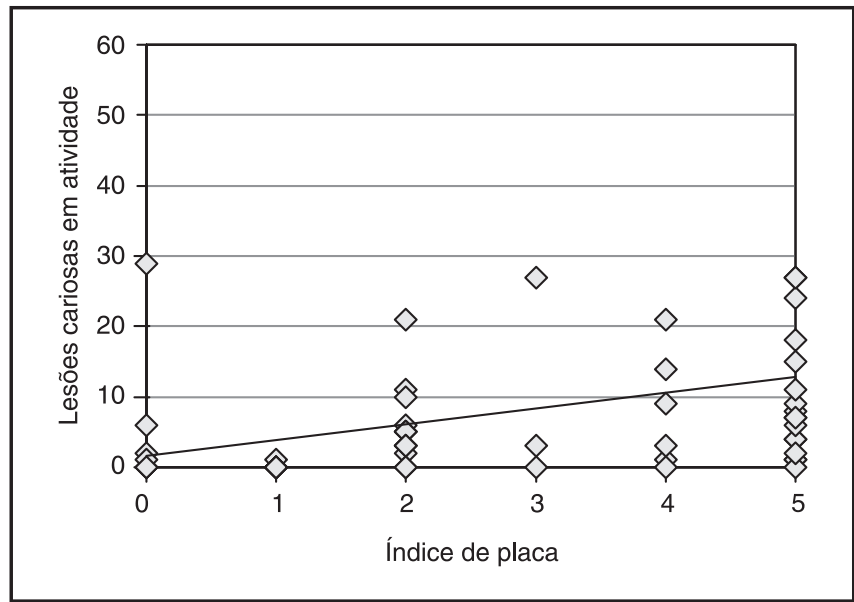

GRÁFICO 3 - Correlação entre o número de superficies dentais com lesões ativas e o índice de biofilme (Ribeiro $\left.^{23}, 2000\right)$, nas crianças soropositivas para o HIV examinadas. Teste de correlação de Spearman: $r_{s}=+0,49$. 
Ribeiro A de A, Portela M, Souza IP de. Relação entre biofilme, atividade de cárie e gengivite em crianças HIV ${ }^{+}$. Pesqui Odontol Bras 2002;16(2):144-150.

como uma gengivite. Sendo esta destruição do periodonto uma manifestação comum da infecção em adultos pelo $\mathrm{HIV}^{8}$, sua prevenção primária seria manter um ótimo estado de saúde gengival. Apesar de a periodontite não ser freqüentemente observada e relatada em crianças $\mathrm{HIV}^{+}$, Soubry et $a l^{26}$ (1995) reportaram 84 casos de doença periodontal em crianças, evidenciando a importância de um adequado controle de placa para a manutenção da saúde dos tecidos gengivais. Por isso, sugere-se a necessidade de desenvolvimento de programas de promoção de saúde baseados em educação e motivação para um adequado controle mecânico de biofilme.

Trabalhos utilizando o índice de placa de Silness, Lö ${ }^{25}$ (1964) demonstraram correlação positiva entre a quantidade de placa e a presença de cárie (CPOD) ${ }^{12,16}$. A observação deste estudo da correlação entre o índice de biofilme (demonstrando a qualidade e localização do acúmulo microbiano) e a atividade de cárie na superficie subjacente (Gráfico 2) reforça a afirmativa "dentes limpos nunca ficam cariados". A maioria dos trabalhos consultados na literatura utilizam o indice CPOD/ceod para apresentar os dados epidemiológicos sobre a experiência de cárie de uma população. Porém, com a evolução da Odontologia, cada vez se torna mais necessário o estabelecimento de índices voltados para a saúde bucal, ao invés dos voltados para a enfermidade. O indice CPOD é um dos mais utilizados, apesar de estar ligado a sinais passados, resultantes da doença, uma vez que, a partir dele, verifica-se a incidência ou prevalência dos dentes cariados, perdidos e obturados; e não é revelado se a doença cárie está presente ou não. Mas um dos fatores mais importantes na avaliação do paciente, para o correto diagnóstico e elaboração do plano de tratamento, é identificar se o fator etiológico da enfermidade está presente, e se a doença está em atividade ou não. A proposta de avaliação, utilizada no presente estudo, permitiu verificar que a grande maioria das crianças $(73,2 \%)$ apre-

\section{REFERÊNCIAS}

1. Ainamo J, Bay I. Problems and proposals for recording gingivitis and plaque. Int Dent J 1975;25:229-35.

2. Axelsson P, Lindhe J. The effect of a preventive programme on dental plaque, gingivitis and caries in schoolchildren. Results after one and two years. J Clin Periodontol 1974; 1:126-38.

3. Basley J, Hoff R, Mofenson L, et al. 1994 Revised classification system for human immunodeficiency virus infection in children less than 13 years of age. MMWR 1994;43:1-11. sentava doença na cavidade bucal, expressa pela atividade de cárie. Ainda mais, a Tabela 2 demonstra uma média de 8,03 superficies dentais com atividade de lesão.

Ainamo, Bay ${ }^{1}$ (1975) sugeriram que o objetivo de desenvolver novos índices deveria ser a criação de uma ferramenta com escores de fácil utilização, não somente para o pesquisador, mas para o clínico também; e ser capaz de ensinar ao paciente a ver o biofilme, o sinal da doença, motivando-o a alcançar um nível aceitável de qualidade de limpeza. Parece que esta mudança e conscientização sugerida por estes autores vem crescendo entre a comunidade científica, com relação à necessidade de observação da presença de biofilme visivel, tanto na realização de levantamentos epidemiológicos, quanto para educação do paciente. Portanto, sugere-se que a utilização do índice de biofilme visível pode ser de grande valia em levantamentos epidemiológicos, pois permite fácil e rápida realização e reflete a realidade sobre o dinâmico processo saúde-doença. Além disso, sua utilização na prática clínica e em programas de promoção de saúde possibilitaria individualizar o tratamento a cada paciente e monitorar sua cooperação.

Diante dos resultados observados quanto a saúde bucal destas crianças infectadas pelo HIV, cabe ainda ressaltar a necessidade de desenvolvimento de programas de promoção de saúde baseados em educação e motivação para um adequado controle mecânico de biofilme, visto que este fator etiológico da doença cárie e gengivite pode e deve ser monitorado, contribuindo assim para uma melhora nas condições bucais desta população.

\section{CONCLUSÃO}

Nas crianças avaliadas, soropositivas para o HIV, foi observada correlação entre a presença e maturação de biofilme (qualidade do biofilme) e a atividade de doença (tanto cárie como gengivite).

4. Bjorndal L, Larsen T, Thylstrup A. A clinical and microbiological study of deep carious lesions during stepwise excavation using long treatment intervals. Caries Res 1997; 31:411-7.

5. Cancro LP, Fischman SL. The expected effect on oral health of dental plaque control through mechanical removal. Periodontology 2000 1995;8:60-74.

6. Carvalho JC, Thylstrup A, Ekstrand KR. Results after 3 years of non-operative occlusal caries treatment of erup- 
Ribeiro A de A, Portela M, Souza IP de. Relação entre biofilme, atividade de cárie e gengivite em crianças HIV ${ }^{+}$. Pesqui Odontol Bras 2002;16(2):144-150.

ting permanent molars. Community Dent Oral Epidemiol 1992;20:187-92.

7. Castro GF, Souza IP, Chianca TK, Hugo R. Avaliação de um programa de prevenção de cárie em crianças HIV+. [resumo 100]. In: $14^{\text {a }}$ Reunião Anual da Sociedade Brasileira de Pesquisa Odontológica 1997; São Paulo. Anais. São Paulo : Sociedade Brasileira de Pesquisa Odontológica; 1997.

8. EC-CLEARINGHOUSE on oral problems related to HIV infection and WHO collaborating centre on oral manifestations of the immunodeficiency virus. Classification and diagnostic criteria for oral lesions in HIV infection. J Oral Pathol Med 1993;22:289-91.

9. Ekstrand KR, Bruun G, Bruun M. Plaque and gingival status as indicators for caries progression on approximal surfaces. Caries Res 1998;32:41-5.

10. Falloon J, Eddy J, Wiener L, Pizzo PA. Human immunodeficiency virus infection in children. J Ped 1989;114:1-30.

11. Fitzgerald RJ, Jordan GV, Stanley HR. Experimental caries and gingival pathological changes in gnotobiotic rat. J Dent Res 1960;39:923-35..

12. Hamp SE, Lindhe J, Fornell J, Johansson LA, Karsson R. Effect of a field program based on systematic plaque control on caries and gingivitis in schoolchildren after 3 years. Community Dent Oral Epidemiol 1978;6:17-23.

13. Howell RB, Jandinski J, Palumbo P, Shey Z, Houpt M. Dental caries in HIV infected children. Ped Dent 1992; 14:370-1.

14. Howell RB, Jandinski J, Palumbo P, Shey Z, Houpt M. Oral soft tissue manifestations and CD4 lymphocyte counts in HIV-infected children. Ped Dent 1996;18:117-20.

15. Jadinski J, Catalanotto F, Murray P, Katz R, Varagiannis E. Oral pathology in pediatric AIDS. [abstract 2705] J Dent Res 1994;73:440.

16. Lindhe J, Axelsson P. The effect of controlled oral hygiene and topical fluoride application on caries and gingivitis in Swedish schoolchildren. Community Dent Oral Epidemiol 1973;1:9-16.

17. Löe H, Theilade E, Jensen SB. Experimental gingivitis in man. J Periodontol 1965;36:177-87.

18. Madigan A, et al. Caries experience and cariogenic markers in HIV-positive children and their siblings. Ped Dent 1996;18:129-36.
19. Maguire A, Rugg-Gunn AJ, Butler TJ. Dental health of children taking antimicrobial and non-antimicrobial liquid oral medication long-term. Caries Res 1996;30:16-21.

20. Neves AA, Tura LF. Conhecimentos e atitudes de responsáveis por crianças HIV+. [resumo 263]. In: 12 ${ }^{\text {a }}$ Reunião Anual da Sociedade Brasileira de Pesquisa Odontológica 1995; São Paulo. Anais. São Paulo : Sociedade Brasileira de Pesquisa Odontológica, 1995.

21. Phelan J, et al. Oral health care for adults, Adolescents and children with HIV infection. New York: Aids Institute, Department of Health; 1998.

22. Rachid M, Schechter M. Manual de HIV/AIDS. Rio de Janeiro: Revinter; 1998.

23. Ribeiro AA. Avaliação de um programa de promoção de saúde bucal em crianças HIV+. [Dissertação Mestrado]. Rio de Janeiro: Universidade Federal do Rio de Janeiro; 2000 .

24. Ribeiro AA, Bundzman ER, Nishio C, Souza IPR. Relation between salivary flow, medicines and caries in HIV+ children. [abstract 1676]. J Dental Res 1998;77:841.

25. Silness J, Löe H. Periodontal disease in pregnancy. II. Correlation between oral hygiene and periodontal condition. Acta Odontol Scand 1964;22:112-35.

26. Soubry R, Taelman H, Banyangiliki V, Ladner J, van der Perre P. Necrotizing periodontal disease in HIV-1-infected patients: a 4-year study in Kigali, Rwanda. In: Greenspan JS, Greenspan B. Oral manifestations of HIV infection. Carol Stream: Quintessence Inc; 1995. p. 60-67.

27. Thylstrup A, Bruun C. The use of dentifrices in the treatment of dental caries. In: Embery G, Rølla G. Clinical and biological aspects of dentifrices. Oxford: Oxford University Press; 1992. p. 132-143.

28. Thylstrup A, Fejerskov O. Textbook of clinical cariology. 2. ed. Copenhagen: Muskgaard; 1994. p. 111-48.

29. Thylstrup A. When is caries caries, and what should we do about it? Quintessence Int 1998;29:549-98.

30. Vieira AR, Souza IPR, Modesto A, Castro GF, Vianna R. Gingival status of HIV+ children and the correlation with caries incidence and immunologic profile. Ped Dent 1998;20:169-72.

Recebido para publicação em 16/07/2001

Enviado para reformulação em 06/02/2002

Aceito para publicação em 25/03/2002 